\title{
Effect of diluent variation on cryopreservation of large yellow croaker Larimichthys crocea
}

\author{
Han Kyu Lim', Zidni Irfan', Hyo Bin Lee', Ji Hoon Song ${ }^{2}$, Yun Ho Lee ${ }^{1, *}$ \\ ${ }^{1}$ Department of Interdisciplinary Program of Biomedicine, Health \& Life Convergence Sciences, Mokpo National University, Mokpo 58554, Korea \\ ${ }^{2}$ Ocean \& Fisheries Science Institute Resources Creation Research Institute, Shinan-gun 58813, Korea
}

\begin{abstract}
The aim of this research was to investigate different factors, including cryoprotective agents (CPAs), diluents, dilution ratios, equilibrium times, freezing rates, and thawing methods to optimize cryopreservation protocols for large yellow croaker (Larimichthys crocea). The parameters evaluated were sperm motility, sperm activity index (SAI), survival rate, and DNA damage. Different types of CPAs, such as dimethyl sulfoxide (DMSO), propylene glycol (PG), ethylene glycol (EG), methanol, and glycerol, were tested for sperm preservation. The highest motility, SAI, and survival rate were observed when EG was used. Different diluents such as Stein's solution, Hank's balanced salt solution, marine fish Ringer's solution, artificial seminal plasma (ASP) of small yellow croaker, and Cortland solution were investigated. The highest post-thaw motility was observed upon using ASP as the diluent. Different concentrations of EG were then mixed with ASP to identify the optimal EG concentration. Experimental results showed that the motility $(70.33 \pm 1.20 \%)$, SAI (5), and survival rate $(78.30 \pm 0.42 \%)$ of post-thaw sperm were optimum when $10 \%$ EG and ASP were used as the CPA and diluent of cryopreservation, respectively. Post-thaw sperm motility was high at equilibration times below $150 \mathrm{~s}$ and at an optimum dilution ratio of 1:1 (sperm: CPA + diluent) and was not significantly different compared with fresh sperm motility. The freezing rate was found to be slow below $-10^{\circ} \mathrm{C} / \mathrm{min}$. The thawing temperature of $45^{\circ} \mathrm{C}$ was identified as ideal. The percentage of tail DNA in post-thaw sperm at 10\% EG and ASP was also investigated and was found to have more significant DNA damage than that in fresh sperm but significantly lower damage than that in post-thaw sperm at EG concentrations of 5\%, 15\%, and 20\% $(p<0.05)$. The cryopreservation protocols obtained in this study will be useful in large yellow croaker hatcheries.
\end{abstract}

Keywords: Cryopreservation, Cryoprotective agents, Sperm motility, Large yellow croaker

\section{Introduction}

Cryopreservation is a valuable technique that assists in the genetic improvement of cultured gametes and provides a continuous supply of high-quality sperm for artificial insemination.
It is of interest not only for fish farming but also for the conservation and genetic improvement of resources. Cryopreservation has been successfully established in freshwater fish species, such as salmons, sturgeons, and carps, and has recently been actively researched in marine fish (Le et al., 2011a, 2011b). Fish

Received: Dec 28, 2020 Revised: Jan 18, 2021 Accepted: Jan 20, 2021

${ }^{\star}$ Corresponding author: Yun Ho Lee

Department of Interdisciplinary Program of Biomedicine, Health \& Life Convergence Sciences, Mokpo National University, Mokpo 58554, Korea Tel: +82-61-450-2395, Fax: +82-61-452-8875, E-mail: hodj66@naver.com, ORCID: https://orcid.org/0000-0001-9356-3037

This is an Open Access article distributed under the terms of the Creative Commons Attribution Non-Commercial License (http://creativecommons.org/licenses/by$\mathrm{nc} / 4.0 /$ ) which permits unrestricted non-commercial use, distribution, and reproduction in any medium, provided the original work is properly cited.

Copyright $\odot 2021$ The Korean Society of Fisheries and Aquatic Science 
sperm preservation is advantageous for solving the unbalanced sex ratio and the asynchronous eggs and sperm discharge time between females and males during spawning season (Chang et al., 1997). Thus, sperm cryopreservation at the gamete level may have many advantages and is already being used in broodstock and medical fields worldwide. Due to the lack of awareness of cryopreservation in Korea thus far, it is necessary to develop basic technologies that can be applied to the actual aquaculture field and conduct physiological research on cryopreserved sperm in aquaculture. In addition, because the types and concentrations of cryoprotective agents (CPAs) and diluents can cause remarkable differences in cryopreservation results, basic information on cryopreservation of fish sperm is necessary (Lee et al., 2021). CPAs play a role in alleviating and regulating conditions unfavorable to cell survival, such as concentration of intracellular electrolytes, increase in osmolality, and formation of ice crystals inside and outside cells, which are generated during the freezing of cells (Ahn et al., 2018). The diluted solution actively helps in the survival of the sperm after freezing and thawing and prevents the sperm from being activated by osmotic shock, with osmolality similar to that of the semen used (Kho \& Kang, 2003; Zidni et al., 2020). Present studies on cryopreservation of the family Sciaenidae have been conducted by many researchers, both domestic and foreign (Gwo, 1993; Gwo, 1994; Le et al., 2011a; Lim et al., 2010). The first protocol for large yellow croaker sperm cryopreservation was published using different CPAs and diluents (Lee \& You, 2002; Lin et al., 2006; Xiao et al., 2007; Xu et al., 2014). However, effective storage methods for gametes of large yellow croaker (Larimichthys crocea) have not been identified.

The study species, large yellow croaker, belonging to the family Sciaenidae, is an economically important fishery resource in Korea. Currently, the quantity of domestic resources has decreased significantly, and the dependence on imports is gradually increasing. Seed production of large yellow croaker faces many problems as follows: 1) the sensitive nature of the fish results in severe stress during transportation; 2) many cases of death due to injuries caused by severe struggle have been reported; 3 ) when seeds are produced, the sex ratio is not balanced or the timing of the male and female spawning and spinning is not synchronized. Thus, to solve these problems, it is necessary to restore the resources through aquaculture. Accordingly, this study aimed to develop a cryopreservation protocol for large yellow croaker.

\section{Materials and Methods}

\section{Fish and sperm collection}

The experiment was conducted from April to July 2020. Adult large yellow croakers were reared in a fiber cylinder fish tank equipped with recirculation systems containing seawater, at a temperature range of $16^{\circ} \mathrm{C}-19^{\circ} \mathrm{C}$, with salinity of $30.2 \pm 1.2 \mathrm{psu}$, dissolved oxygen of $7.1 \mathrm{mg} \cdot \mathrm{L}^{-1}$, and $\mathrm{pH}$ of 8.1, at Ocean \& Fisheries Science Institute Resources Creation Research Institute, Shinan-gun, Korea. The mean length and body weight of males ( $\mathrm{n}=15$ ) were $19.4 \pm 2.7 \mathrm{~cm}$ and $80.67 \pm 4.53 \mathrm{~g}$, respectively. During the study, the fish were fed with a commercial diet once a day in the morning. After acclimation, fish were anaesthetized with tricaine methanesulfonate (MS-222) and Ovaprim $(0.1 \mathrm{~mL}$ $\mathrm{kg}^{-1}$; Syndel Laboratories, Nanaimo, BC, Canada) was injected into the ventral muscle (intraperitoneally) of the males. To prevent any mixing with feces, blood, water, urine, and mucous, the area around the genitals of male fish was cleaned using paper towels. The sperm was stripped into plastic syringes $(1.0 \mathrm{~mL})$ by applying gentle pressure to the ventral muscle and the syringes containing sperm were then placed in an icebox and directly taken to the laboratory for analysis, observation, and cryopreservation. The sperm samples selected for use in the study had a total motility of more than $80 \%$ and a sperm activity index (SAI) of 5 .

\section{Evaluation of sperm motility}

Sperm motility was analyzed after collecting the sperm samples. To measure sperm motility, sperm samples were diluted in seawater at a ratio of $1: 100(10 \mu \mathrm{L}$ fresh sperm to $1,000 \mu \mathrm{L}$ seawater). Subsequently, $10 \mu \mathrm{L}$ of the mixture (sperm + sea water) was dropped onto a glass slide without a cover slip and observed under a microscope at 200× magnification (CH30, Olympus, Tokyo, Japan). To investigate the post-thawing sperm quality after each cryopreservation treatment, movable sperm ratio (MSR) and SAI were estimated. MSR was calculated according to the method described by Ahn et al. (2018), which states that MSR is the ratio between moving sperm count to the total count of fresh/post thawing sperm investigated with a microscope at $200 \times$ magnification (CH30, Olympus). SAI was measured as follows: (index score $\times$ motile sperm ratio [\%]) / 100. The calculation of the index score (scoring method) was based on the characteristics of the movement of the sperm (quick, slow, vibration, and motility) (Table 1). To evaluate MSR and SAI of cryopreserved sperm, artificial seawater containing 
Table 1. Numerical index for the evaluation of sperm motility

\begin{tabular}{lll}
\hline Index & Score & Motility characteristics \\
\hline I & 5 & Rapid forward movement \\
II & 4 & Slow forward movement \\
III & 3 & Slow forward movement and moderate vibrating movement \\
IV & 2 & Slow vibrating movement \\
V & 1 & Immobility \\
\hline
\end{tabular}

Sperm activity index $($ SAl $)=[$ Index score $\times$ Movable sperm ratio $(\%)] \times 100$.

$27 \mathrm{~g} \mathrm{NaCl}, 0.5 \mathrm{~g} \mathrm{KCl}, 1.2 \mathrm{~g} \mathrm{CaCl}_{2}, 4.6 \mathrm{~g} \mathrm{MgCl}_{2}$, and $0.5 \mathrm{~g} \mathrm{NaH}-$ $\mathrm{CO}_{3}$ per liter of distilled water was used as a diluent at a ratio of 1:99 (sperm: artificial seawater) according to the protocol by Le et al. (2011b). Subsequently, $1 \mu \mathrm{L}$ of the mixture was placed onto a glass slide (Teflon printed glass slide; 21 wells; diameter of each well, $4 \mathrm{~mm}$; Funakoshi, Tokyo, Japan) without a cover slip. Furthermore, cryopreserved sperm quality was investigated immediately after thawing in a $20^{\circ} \mathrm{C}$ water bath for $10 \mathrm{~s}$ through observation under a microscope at $200 \times$ magnification. Triplicate experiments were conducted for each treatment and replicated three times.

\section{CPAs and diluents}

In the first experiment, five cryoprotectants, ethylene glycol (EG), dimethyl sulfoxide (DMSO), propylene glycol (PG), glycerol, and methanol, were tested for their effect on sperm quality after cryopreservation in large yellow croaker. All cryoprotectants were applied at a final concentration of $10 \%$. Cortland solution was used as a diluent, and each mixture (CPA + diluent) was placed into a $1.5 \mathrm{~mL}$ tube. The ratio between sperm and the mixture was 1:3. At this stage, the equilibration time was not adjusted. The mixture was applied to $0.25 \mathrm{~mL}$ plastic cryopreservation straws that were subsequently sealed and frozen. The sperm was first frozen for $2 \mathrm{~min}$ in a tray (size: $8.5 \mathrm{~cm}$ wide and $20 \mathrm{~cm}$ long) at $3 \mathrm{~cm}$ above liquid nitrogen (LN) in a Styrofoam box, with a lid covering the box to maintain the first freezing temperature; then, it was submerged in $\mathrm{LN}\left(-196^{\circ} \mathrm{C}\right)$ for the second phase of freezing (Ahn et al., 2018; Le et al., 2008; Lim et al., 2007). Fresh sperm from the same male fish was considered the control.

The second experiment was conducted to observe the effects of different diluents, including Stein's solution (SS), Hanks' balanced salt solution (HBBS), marine fish Ringer's solution (MFRS), artificial seminal plasma (ASP) of small yellow croaker, and Cortland solution, on sperm preservation. The contents of the diluents are presented in Table 2. The composition of ASP was based on the biochemical properties of small yellow croaker seminal plasma (Lim et al., 2010). The CPAs and diluents were precooled at $4^{\circ} \mathrm{C}$ before use (Lee et al., 2021; Zidni et al., 2020). Sperm was separately mixed with various diluents at $10 \%$ EG. Each mixture was frozen and thawed using the same technique as described above.

To measure the optimum EG concentration, a third experiment was conducted because EG was found to be the most efficient CPA for cryopreservation in the first experiment. Different concentrations of EG (5\%,10\%,15\%, and $20 \%)$, were tested with ASP as the diluent. The process of freezing and thawing was the same as that in the previous experiments.

\section{Dilution ratio and equilibrium time}

The prior experiments demonstrated that a combination of $10 \%$ EG and ASP were optimum for sperm cryopreservation in large yellow croakers. To investigate the effect of the dilution ratio, the sperm was diluted at ratios of 1:1, 1:3, 1:5, 1:10, 1:30, 1:100, and 1:200 with ASP containing EG at a final concentration of $10 \%$. The time of equilibration was not specifically set. The freezing and thawing method was the same as described in the prior experiments.

To investigate the optimal equilibrium time, the sperm was diluted at a 1:1 ratio with ASP containing EG at a final concentration of $10 \%$, and the mixture was then allowed to equilibrate for various lengths of time $(30,60,90,120,150,180,210,240$, 270 , and 300 s). During equilibrium, sperm samples were loaded into $0.25 \mathrm{~mL}$ straws (3 replicate straws $\times 10$ equilibrium times) and sealed with sealing powder (Reproduction provisions, LLC, Walworth, WI, USA) at room temperature $22-24.5{ }^{\circ} \mathrm{C}$.

\section{Freezing rate and thawing method}

To investigate the optimal freezing rate, the sperm was frozen under four different freezing rates $\left(-1{ }^{\circ} \mathrm{C},-5^{\circ} \mathrm{C},-10^{\circ} \mathrm{C}\right.$, and $-20^{\circ} \mathrm{C} / \mathrm{min}$ ) using a CRF (14S, SY-LAB, Neupurkersdorf, Austria). The controlled rate freezer was set to start from $10^{\circ} \mathrm{C}$ to $-80^{\circ} \mathrm{C}$ for the first freezing, and then the frozen sperm was stored in LN. During the thawing method, the straws were removed from the LN storage using tweezers and immediately immersed for $10 \mathrm{~s}$ in a water bath at different temperatures $\left(20^{\circ} \mathrm{C}, 25^{\circ} \mathrm{C}, 30^{\circ} \mathrm{C}, 35^{\circ} \mathrm{C}, 40^{\circ} \mathrm{C}, 45^{\circ} \mathrm{C}\right.$, and $\left.50^{\circ} \mathrm{C}\right)$. The straws were removed with tweezers and both sealed ends of the straws were cut off using a straw cutter. Thawed sperm were stored in a microtube and used for evaluation of post-thaw sperm motility. 
Table 2. Constituents of diluents used in the experiments

\begin{tabular}{|c|c|c|c|c|c|}
\hline Ingredient & $\begin{array}{l}\text { Stein's solution } \\
\text { (Stein \& Bayrle, 1978) }\end{array}$ & $\begin{array}{l}\text { Hanks' balanced salt solution } \\
\text { (HBBS) (Bart et al., 1998) }\end{array}$ & $\begin{array}{l}\text { Marine fish Ringer's solution } \\
\text { (MFRS) (Le et al., 2011) }\end{array}$ & $\begin{array}{l}\text { Small yellow croaker ASP } \\
\text { (Le et al., 2011) }\end{array}$ & $\begin{array}{l}\text { Cortland solution } \\
\text { (Cheng et al., 2015) }\end{array}$ \\
\hline $\begin{array}{l}\mathrm{NaCl} \\
\text { (Sodium chloride, g/L) }\end{array}$ & 0.75 & 8.00 & 13.50 & 9.92 & 7.25 \\
\hline $\begin{array}{l}\mathrm{KCl} \\
\text { (Potassium chloride, g/L) }\end{array}$ & 0.038 & 0.40 & 0.60 & 0.77 & 0.38 \\
\hline $\begin{array}{l}\mathrm{CaCl}_{2} \\
\text { (Calcium chloride, } \mathrm{g} / \mathrm{L} \text { ) }\end{array}$ & - & 0.14 & 0.35 & 0.13 & 0.18 \\
\hline $\begin{array}{l}\mathrm{MgSO}_{4} \cdot 7 \mathrm{H}_{2} \mathrm{O} \\
\text { (Magnesium sulphate, g/L) }\end{array}$ & - & 0.20 & - & - & 1.00 \\
\hline $\mathrm{Na}_{2} \mathrm{HPO}_{4} \cdot 7 \mathrm{H}_{2} \mathrm{O}(\mathrm{g} / \mathrm{L})$ & - & 0.06 & - & - & 0.23 \\
\hline $\begin{array}{l}\mathrm{KH}_{2} \mathrm{PO}_{4} \\
\text { (Potassium phosphate, } \mathrm{g} / \mathrm{L} \text { ) }\end{array}$ & - & 0.03 & - & - & 0.41 \\
\hline Hen egg yolk (mL) & 100 & - & - & - & - \\
\hline $\begin{array}{l}\mathrm{C}_{6} \mathrm{H}_{12} \mathrm{O}_{6} \\
\text { (Glucose, g/L) }\end{array}$ & 0.10 & 1.00 & - & 1.00 & 1.00 \\
\hline $\begin{array}{l}\mathrm{NaHCO}_{3} \\
\text { (Sodium bicarbonate, g/L) }\end{array}$ & 0.20 & 0.17 & 0.03 & - & - \\
\hline $\begin{array}{l}\mathrm{MgCl}_{2} \\
\text { (Magnesium chloride, } \mathrm{g} / \mathrm{L} \text { ) }\end{array}$ & - & - & 0.02 & 0.05 & - \\
\hline $\begin{array}{l}\mathrm{NaH}_{2} \mathrm{PO}_{4} \cdot 2 \mathrm{H}_{2} \mathrm{O} \\
\text { (Sodium phosphate, g/L) }\end{array}$ & - & - & - & - & 1.00 \\
\hline
\end{tabular}

\section{Single cell gel electrophoresis (SCGE)}

Even when using the optimal CPA and diluent selected from the previous experiment, the sperm suffered DNA damage during the cryopreservation and thawing processess. SCGE assay (Comet Assay, Trevigen, Gaithersburg, MD, USA) was performed to evaluate DNA damage, and fluorescent staining using SYBR Gold (dilution $\times 10,000 \mathrm{DMSO}$ ) was performed for $30 \mathrm{~min}$, followed by observation under a fluorescence microscope (DM 2500 microscope, Leica, Wetzlar, Germany). Head intensity (DNAh), tail intensity, and tail migration were assessed using Comet Assay IV lite System (Instem, Staffordshire, UK). The percentage of tail DNA was calculated using the following equation: [100 $\times($ DNAc - DNAh)/DNAc] (Cabrita et al., 2005; Lee et al., 2021; Zidni et al., 2020), where DNAc and DNAh are the sum of the intensities of the pixels in the whole comet area and the head area, respectively (Pérez-Cerezales et al., 2009). The degree of damage was categorized and the percentage of cells within each degree of damage was established.

\section{Statistical analysis}

Data were expressed as the mean \pm SE. Statistical evaluation was performed using one-way analysis of variance with IBM SPSS
Statistics 25.0 (USA). Means were analyzed using Duncan's multiple range test, and differences were considered significant at $p<$ 0.05 . The relationships between sperm motility, survival rate, and DNA damage were tested using bivariate Pearson correlation.

\section{Results}

\section{Effects of different CPAs and diluents on post-thaw sperm quality}

The motility parameters recorded in frozen sperm are provided in Fig. 1. The data obtained indicate a significant effect of the CPA used $(p<0.05)$ on motility, SAI, and survival rate. Compared with sperm cryopreserved with other CPAs, the best postthaw motility was recorded for sperm cryopreserved with $10 \%$ EG (56.67 $\pm 2.88 \% ; p<0.05)$, followed by that with $10 \%$ DMSO $(34.33 \pm 1.16 \% ; p<0.05)$. In contrast, PG, methanol, and glycerol resulted in low MSRs. SAI and survival rates were significantly higher for sperm cryopreserved with EG $(4.3 \pm 0.58 \%$ and $73.33 \pm 1.52 \%$, respectively) than for that cryopreserved with other CPAs. When comparing different diluents with $10 \%$ EG, ASP of small yellow croaker resulted in the highest MSR (71.67 $\pm 2.88 \%)$, although this value was not significantly dif- 

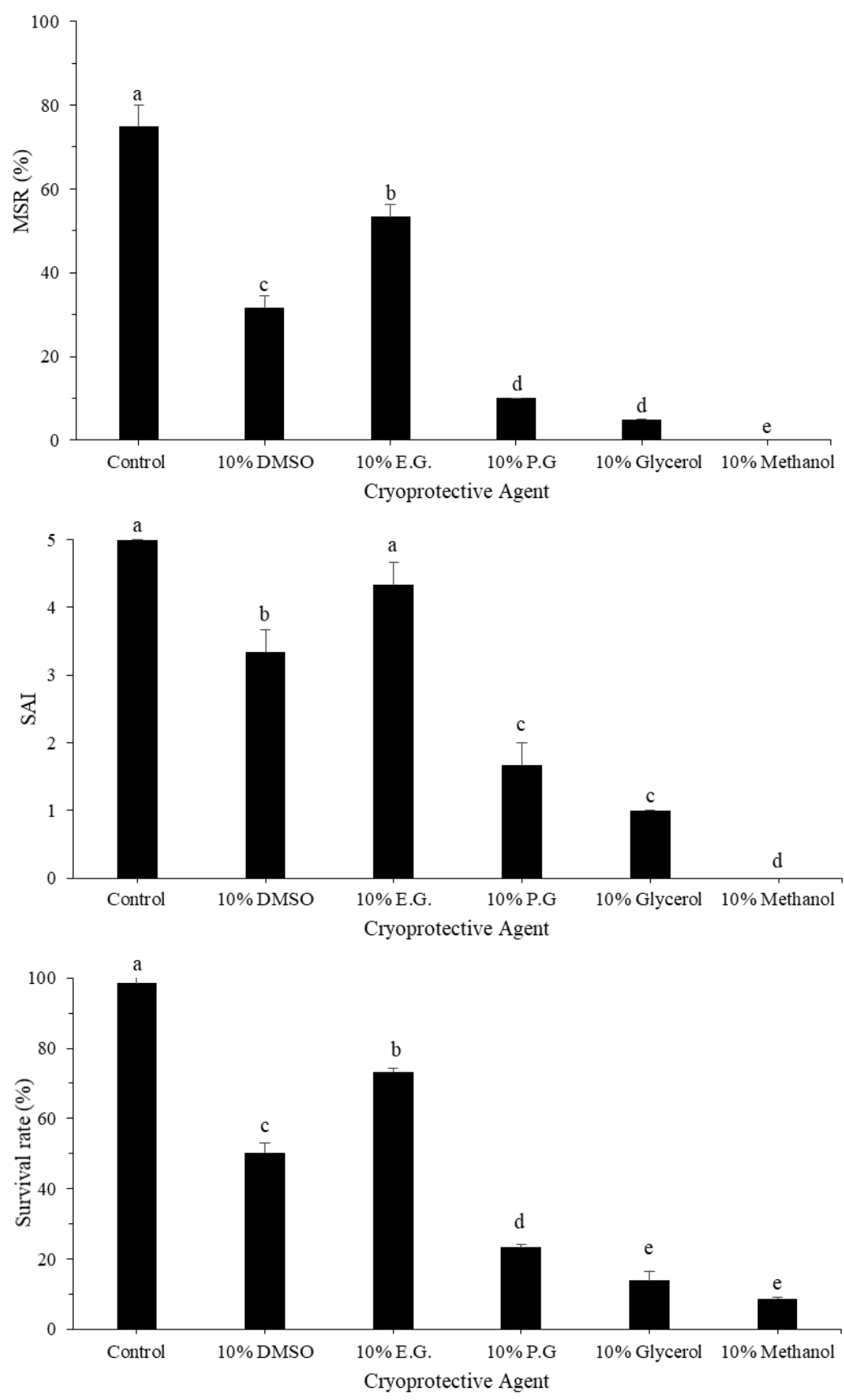

Fig. 1. Movable sperm ratio (MSR), sperm activity index (SAI), and survival rate of post-thaw sperm of large yellow croaker (Larimichthys crocea) upon use of different cryoprotective agents with Cortland solution as a diluent $(p<0.05)$. Control, fresh sperm; DMSO, dimethyl sulfoxide; E.G, ethylene glycol; P.G, propylene glycol.

ferent from that obtained using HBBS $(67.33 \pm 2.51 \%)$. SAI and survival rates were significantly higher for ASP $(4.5 \pm 0.5$ and $75.67 \pm 2.08 \%$, respectively) than for other diluents (Fig. 2). The effect of various concentrations of EG was investigated using ASP as a diluent. Compared with the use of other concentra- tions of EG, the highest MSR (68.33 $\pm 1.66 \%)$ and survival rate (78.30 $\pm 0.42 \%)$ were observed using $10 \%$ EG (Fig. 3). SAI was not significantly different when $5 \%$ and $10 \%$ EG were used but was significantly different on comparing 5\% and 10\% EG and other concentrations. 

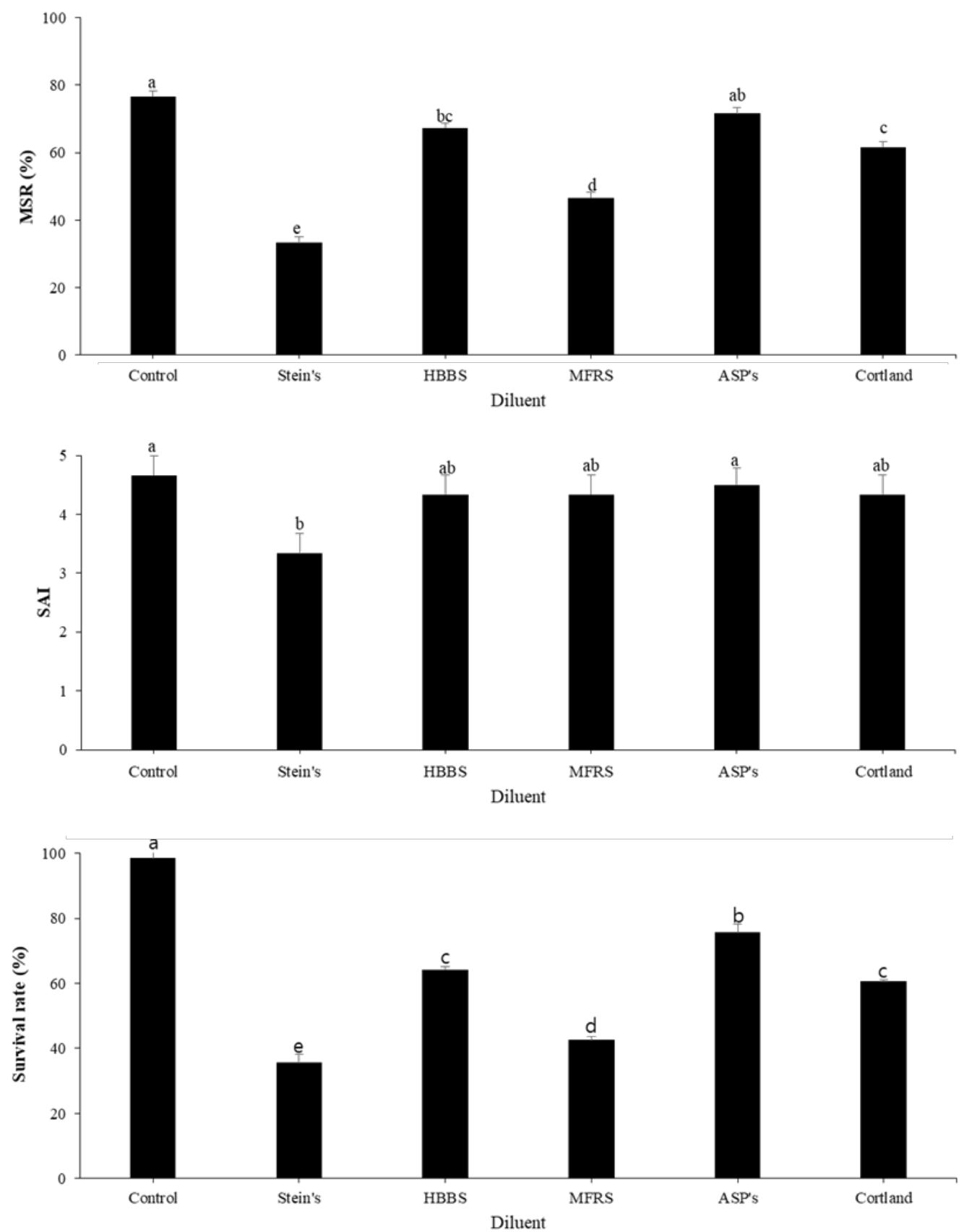

Fig. 2. Movable sperm ratio (MSR), sperm activity index (SAI), and survival rate of post-thaw sperm of large yellow croaker (Larimichthys crocea) upon use of different diluents with $10 \%$ ethylene glycol as a cryoprotective agent $(p<0.05)$. Control, fresh sperm; Stein's, Stein's solution; HBBS, Hanks' balanced salt solution; MFRS, Marine fish Ringer's solution; ASP's, artificial seminal plasma of small yellow croaker; CPA, cryoprotective agent.

\section{Effects of different equilibrium times and dilution ratios on post-thaw sperm motility}

Post-thaw MSR, SAI, and survival rate obtained at various equilibration times during the freezing process are shown in
Fig. 4. Post-thaw MSR in large yellow croakers appeared to be stable up to the equilibration time of $150 \mathrm{~s}$, but post-thaw MSR, SAI, and survival rate significantly decreased $(p<0.05)$ with equilibration times longer than $150 \mathrm{~s}$. The effects of different 

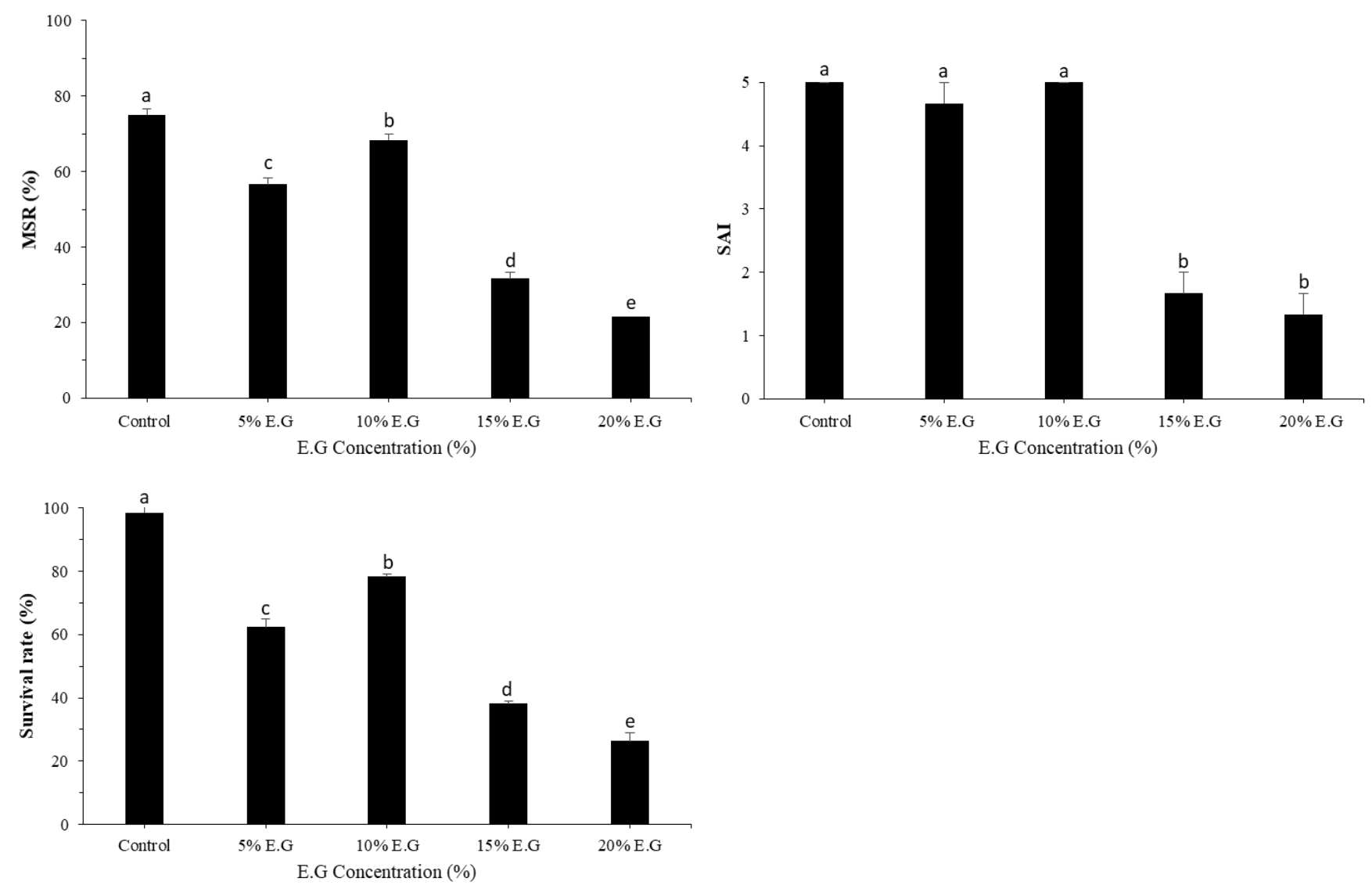

Fig. 3. Movable sperm ratio (MSR), sperm activity index (SAI), and survival rate of post-thaw sperm of large yellow croaker (Larimichthys crocea) upon use of various ethylene glycol concentrations $(\boldsymbol{p}<0.05)$. Ethylene glycol (E.G) with ASP (artificial seminal plasma of small yellow croaker) as a diluent. Control, fresh sperm.

dilution ratios of sperm to the mixture of $\mathrm{CPA}+$ diluent on the motility of post-thaw sperm are shown in Fig. 5. The ratios of 1:1 and $1: 3$ exhibited the highest MSR at $80.67 \pm 0.67 \%$ and 79.33 $\pm 1.20 \%$, respectively, highest SAI of 4.7 for both, and highest survival rates at $95.09 \pm 1.02 \%$ and $93.97 \pm 2.29 \%$, respectively, with no significant difference between both treatments. However, MSR, SAI, and survival rate significantly decreased after treatment with diluent ratios of 1:10-1:200.

\section{Effects of different freezing rates and thawing methods on post-thaw sperm motility}

MSR, SAI, and survival rate of post-thaw sperm at different freezing rates during the sperm freezing process are shown in Fig. 6. The highest MSR was observed at the freezing rate of $-10^{\circ} \mathrm{C} / \mathrm{min}$ $(81.67 \pm 1.67 \%)$, followed by that at the freezing rate of $-5^{\circ} \mathrm{C} / \mathrm{min}$ (79.83 $\pm 1.04 \%)$, with no significant difference between the two treatments. The same freezing rates also resulted in a high surviv- al rate in post-thaw sperm. The SAI value was observed but was no significant difference between the two treatment.

Different thawing methods $\left(20^{\circ} \mathrm{C}, 25^{\circ} \mathrm{C}, 30^{\circ} \mathrm{C}, 35^{\circ} \mathrm{C}, 40^{\circ} \mathrm{C}\right.$, $45^{\circ} \mathrm{C}$, and $50^{\circ} \mathrm{C}$ ) were applied after sperm freezing in the nitrogen tank $\left(-196^{\circ} \mathrm{C}\right)$. The effect of different thawing methods on the post-thaw sperm motility of large yellow croakers are shown in Fig. 7. The best sperm motility was observed after thawing at $45^{\circ} \mathrm{C}$ for $10 \mathrm{~s}(76.67 \pm 1.67 \%)$, followed by that at $40^{\circ} \mathrm{C}(72.33$ $\pm 1.45 \%$ ), with no significant difference between the two methods. The highest survival rate was observed after thawing at $45^{\circ} \mathrm{C}$ for $10 \mathrm{~s}(86.92 \pm 0.77 \%)$. SAI was significantly lower after thawing at $20^{\circ} \mathrm{C}$ for $10 \mathrm{~s}$, but there was no significant difference in SAI between treatments at $25^{\circ} \mathrm{C}-50^{\circ} \mathrm{C}$.

\section{Correlation between MSR, survival rate, and \% tail DNA (CPA concentration and diluent)}

The correlation between large yellow croaker sperm MSR, sur- 

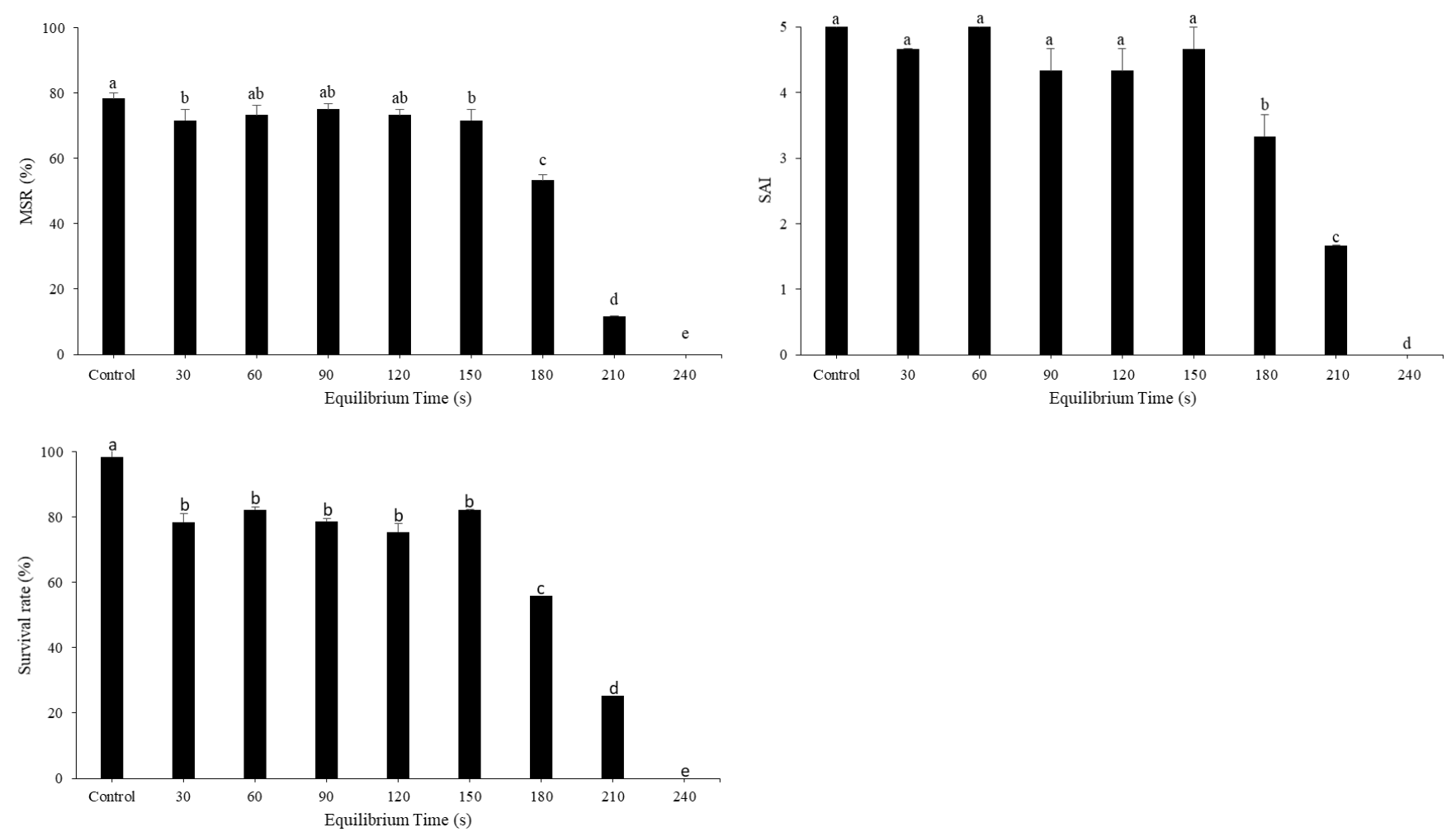

Fig. 4. Movable sperm ratio (MSR), sperm activity index (SAI), and survival rate of post-thaw sperm of large yellow croaker (Larimichthys crocea) upon use of various equilibration times $(p<0.05)$. Control, fresh sperm.

vival rate (\%), and \% tail DNA (CPA concentration, Different Diluent) are shown in Fig. 8. The percentage of tail DNA had a negative correlation to MSR and survival rate $(y=-5.8033 \mathrm{x}+$ 95.258, $\left.R^{2}=0.6045\right)$ with lower \% tail DNA damage occurring with higher sperm MSR and survival rate.

\section{SCGE results}

To investigate DNA damage following cryopreservation, we observed the effect of different E.G concentrations, with ASP as the diluent, on sperm via SCGE. The highest head length and head intensity values were identified in the control (fresh sperm; $56.04 \pm 0.76$ ) followed by $10 \%$ E.G $(86.71 \pm 0.94)$, which were higher than those obtained with other concentrations of E.G. Further, treatment with 10\% ASP showed low levels of tail intensity, percentage of tail DNA, and tail length relative to other treatments but higher levels than those of the control $(p<0.05$; Table 3). The effect of different diluents on cryopreservation damages was observed using 10\% E.G as the CPA. The highest head intensity and the lowest tail intensity, percent tail DNA, and tail length values were found when ASP was used as the diluent (Table 4).

\section{Discussion}

Sperm cryopreservation is one of the most important biotechnological techniques in aquaculture and has many advantages. Understanding the physiology of gametes and the biochemical processes occurring during sperm collection, processing, freezing, and thawing is important for improving sperm cryopreservation techniques (Berlinsky et al., 1997; Cabrita et al., 2005; Suquet et al., 2000). Several factors affect post-thaw sperm motility, including sperm quality, diluent, CPA, equilibration time, freezing rate, dilution ratio, and thawing temperature (Chang et al., 1997). Among these factors, the role of CPA is particularly important. Most cryopreservation injuries can be avoided at high CPA concentrations, but at the same time, the CPA may be toxic to the cells (Bozkurt \& Yavas, 2016). In the current study, frozen-thawed sperm motility was evaluated using $10 \% \mathrm{EG}$, which is an effective CPA for large yellow croaker sperm cryopreservation. In addition, 10\% DMSO exhibited the 

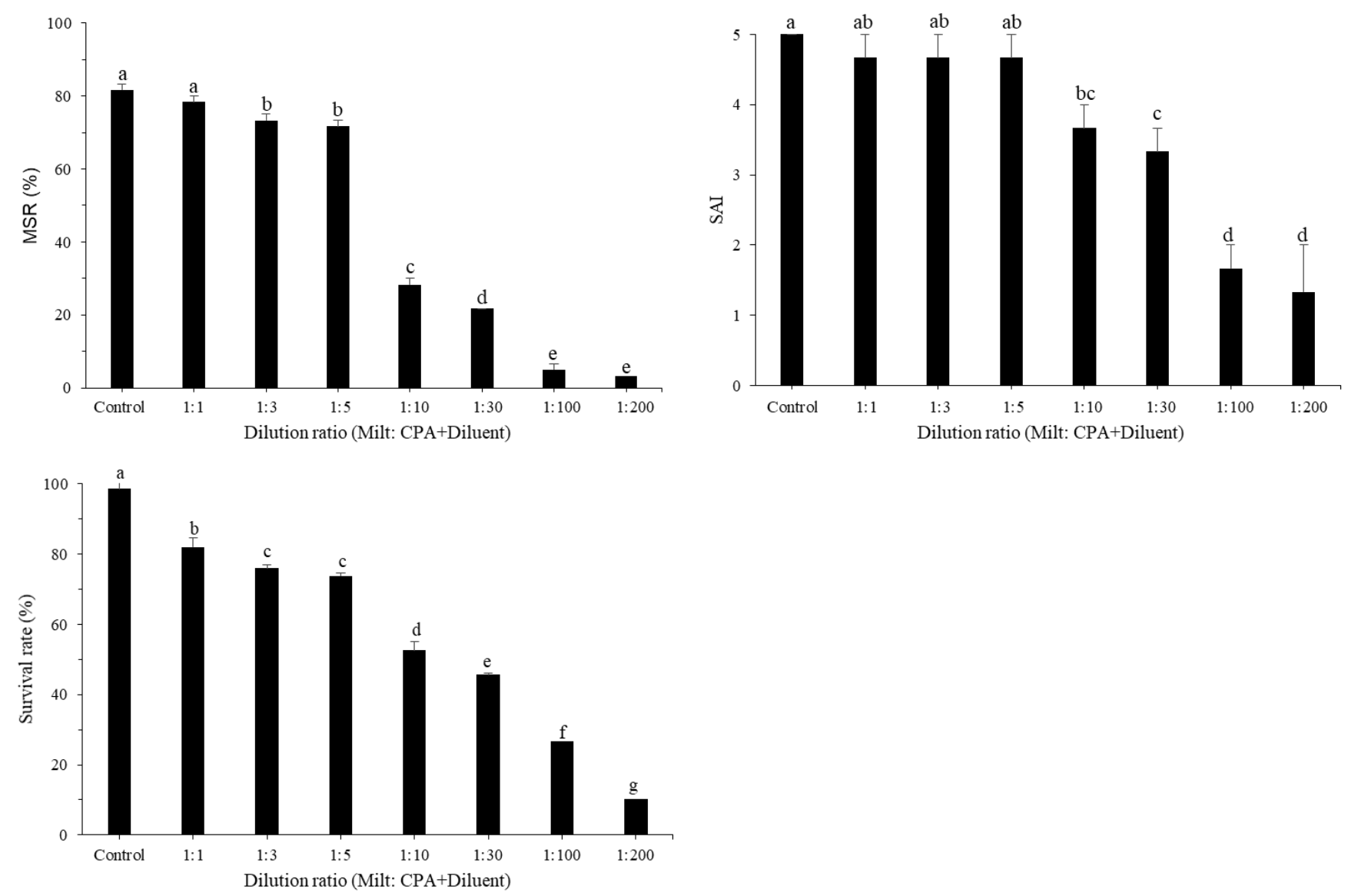

Fig. 5. Movable sperm ratio (MSR), sperm activity index (SAI), and survival rate of post-thaw sperm of large yellow croaker (Larimichthys crocea) upon use of various dilution rates (sperm: CPA + diluent) of sperm $(p<0.05)$. Control, fresh sperm; CPA, cryoprotectant agent.

second best motility ratio in frozen-thawed sperm. This result is similar to that of the study by Jian et al. (2011), who found that there was no significant difference in sperm viability between fresh sperm and frozen-thawed sperm of large yellow croaker when using $5 \%-20 \%$ EG or DMSO as the CPA. According to Xiao et al. (2007), the use of $10 \%$ DMSO as CPA showed higher sperm motility in large yellow croakers. In another species of croaker, Le et al. (2011) observed EG to be the best CPA to preserve the quality of frozen-thawed small yellow croaker sperm. In this report, methanol, glycerol, and PG were not suitable in combination with ASP as a diluent because they produced frozen-thawed sperm with low motility. However, some studies have shown glycerol to be an effective CPA in sperm cryopreservation of large yellow croakers (Lee \& You, 2002; Xiao et al., 2007). Differences in the effectiveness of CPAs may occur within the same species owing to the differences in the diluents combined with them (Zidni et al., 2020). Moreover, various characteristics of the CPA and the diluent used may affect the maintenance of sperm. Cryoprotectants are important for the protection of the sperm from cold and heat-shock treatments and for the prevention of cell dehydration (Le et al., 2011; Lim et al., 2007). CPAs can also be used to avoid the formation of ice during pre-freezing, but the same levels of CPA can be lethal to unfrozen cells (Cabrita et al., 2010; Chao \& Liao, 2001; Cloud \& Patton, 2008; Kopeika et al., 2007; Suquet et al., 2000).

Like CPAs, diluents also play an important role in sperm cryopreservation, particularly for long-term cryopreservation. Diluents perform critical functions as regulators of osmotic pressure, $\mathrm{pH}$, and ionic components. In this study, ASP use resulted in high MSR, with no significant difference between ASP-treated cryopreserved sperm and fresh sperm. HBBS and Cortland solution were also good diluents in cryopreservation 

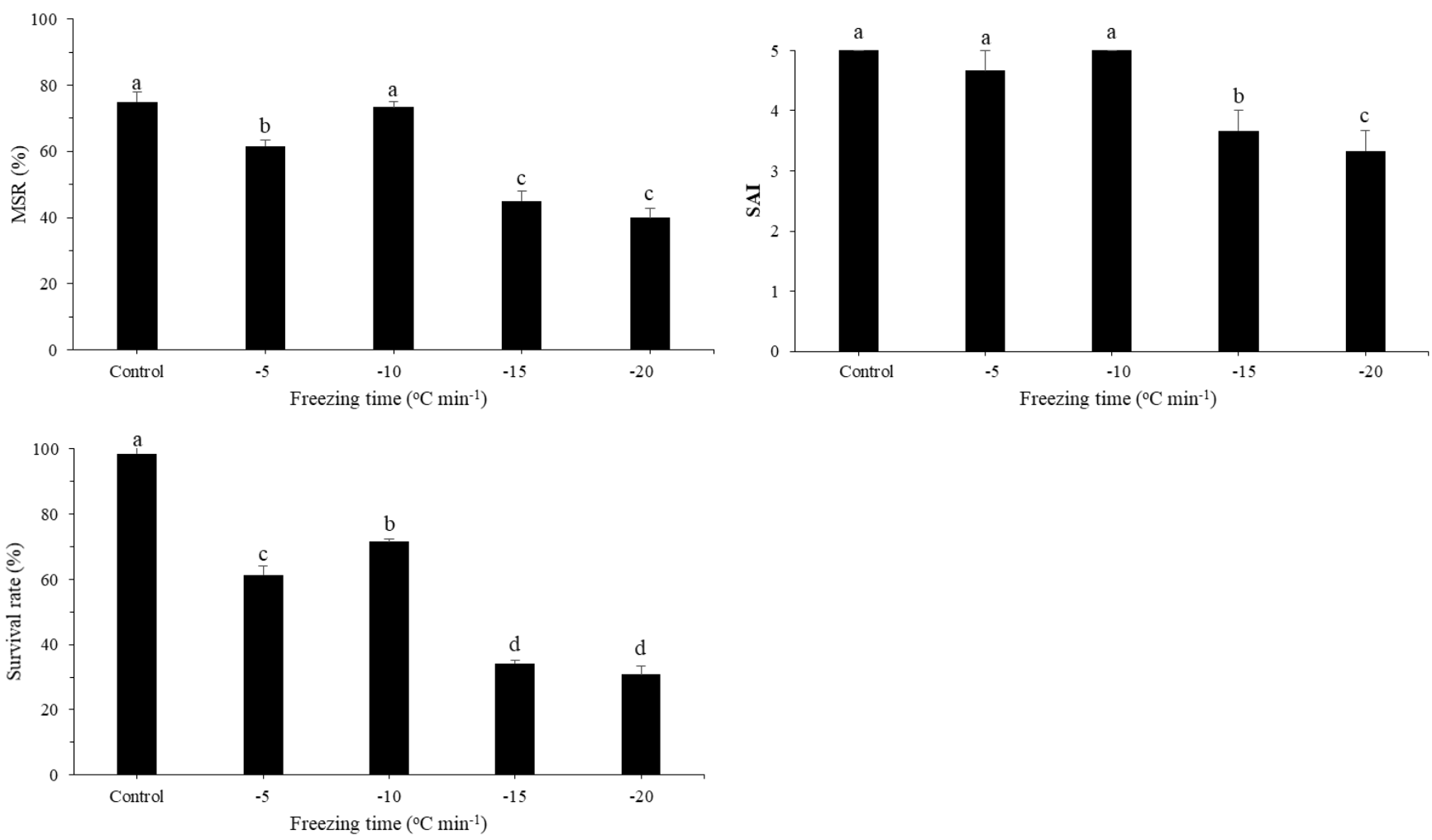

Fig. 6. Movable sperm ratio (MSR), sperm activity index (SAI), and survival rate of post-thaw sperm of large yellow croaker (Larimichthys crocea) upon use of different freezing rates $(p<0.05)$. Control, fresh sperm.

of large yellow croakers, but SS and MFRS resulted in lower frozen-thawed sperm motility. We found that ASP was the best diluent in this investigation. ASP as a diluent is effective because it is based on yellow croaker seminal plasma (Le et al., 2011; Lim et al., 2007). The use of ASP as a diluent in fish sperm cryopreservation has been extensively investigated for a variety of fish species (Le et al., 2008; Lim \& Le, 2013). HBBS and Cortland solution have already been used as diluents for cryopreservation in large yellow croakers and have resulted in good motility of frozen-thawed sperm (Cheng et al., 2015; Jian et al., 2011; Xiao et al., 2007; Xu et al., 2014).

The optimal equilibration time varies among different species and within the same species depending on the type and quantity of CPA/diluent used (Betsy \& Kumar, 2020). For effective protection during cooling, sufficient time should be given to facilitate the penetration of CPAs into sperms. In the present study, equilibrium times up to $150 \mathrm{~s}$ were effective at maintaining motility at the same level as that of the control. However, decreased sperm motility was correlated with equilibration times longer than $150 \mathrm{~s}$. Sufficient time should be provided for effective protection during cooling to promote the absorption of cryoprotectants into sperms. Because the sperm is sufficiently small and DMSO penetration is rapid, no lengthy equilibration time is required for this CPA (Harvey, 1983).

Dilution ratios could be a significant factor in the efficiency of cryopreservation. In our study, higher motility of the cryopreserved sperm was observed when the ratio of 1:1 was used. Increasing the dilution ratio from 1:10 to 1:200 reduced the percentage of MSR, SAI, and survival rate. A previous study on cryopreservation of large yellow croakers showed higher motility of post-thaw sperm on using the dilution ratio of 1:3 (Jian et al., 2011; Lee \& You, 2002; Lin et al., 2006; Xiao et al., 2007). For cryopreservation of fish sperm, the optimum dilution ratio is often represented by a variety of species-specific values from 1:1 to 1:20 (Suquet et al., 2000), and higher dilution ratios generally result in reduced percentage of motile sperm, SAI, and sperm survival rate. The motility duration of black grouper spermatozoa decreased from $40 \mathrm{~min}$ to $2 \mathrm{~min}$ with an increase in the semen dilution ratio from 1:10 to $1: 100$ (Gwo, 1993). Increasing the dilution rate from 1:1 to 1:9 did not modify the percentage of motile 

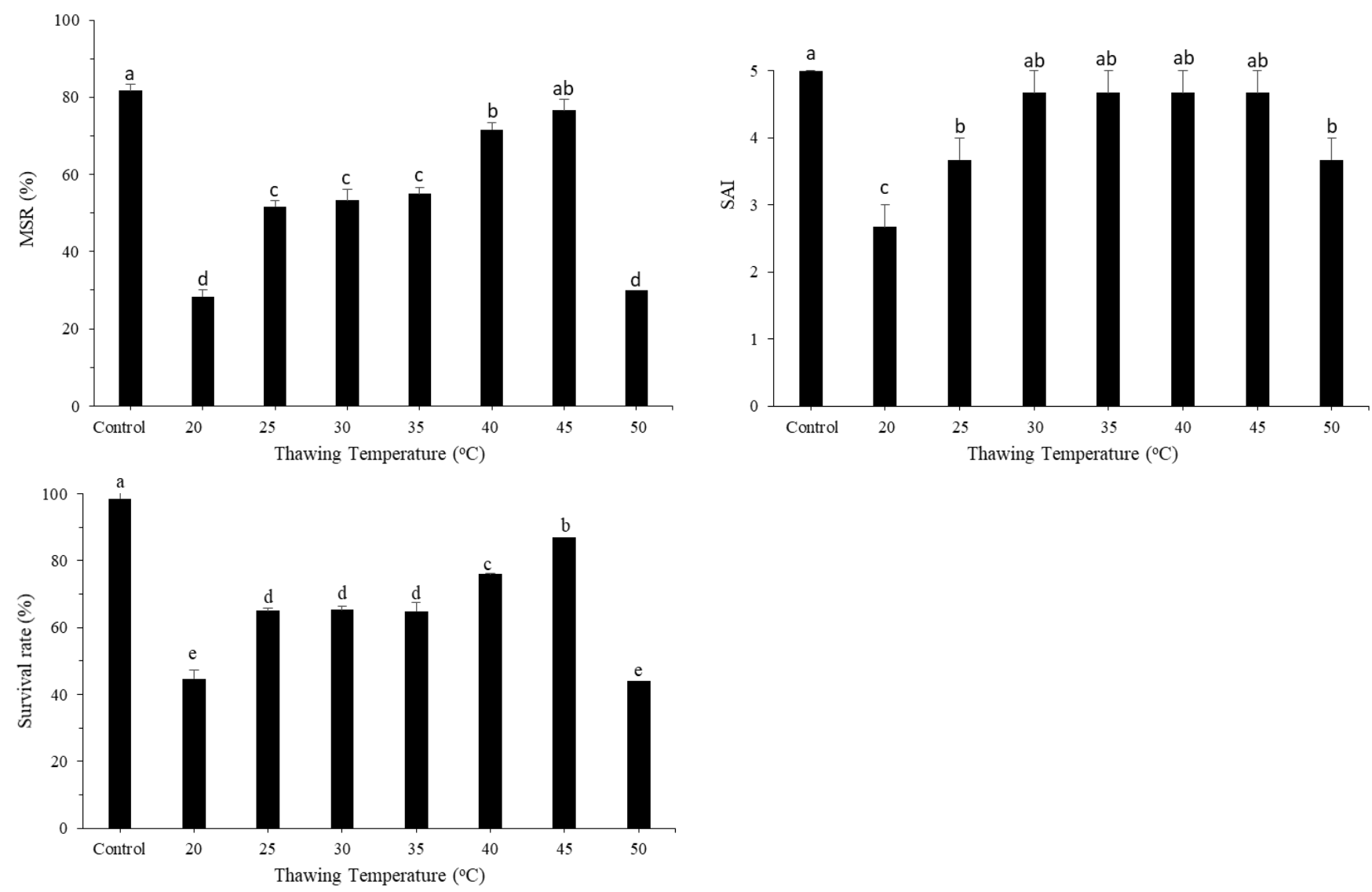

Fig. 7. Movable sperm ratio (MSR), sperm activity index (SAI), and survival rate of post-thaw sperm of large yellow croaker (Larimichthys crocea) upon use of different thawing methods $(p<0.05)$. Control, fresh sperm.

_ Correlation \% Tail DNA, MSR, Survival rate (\%)

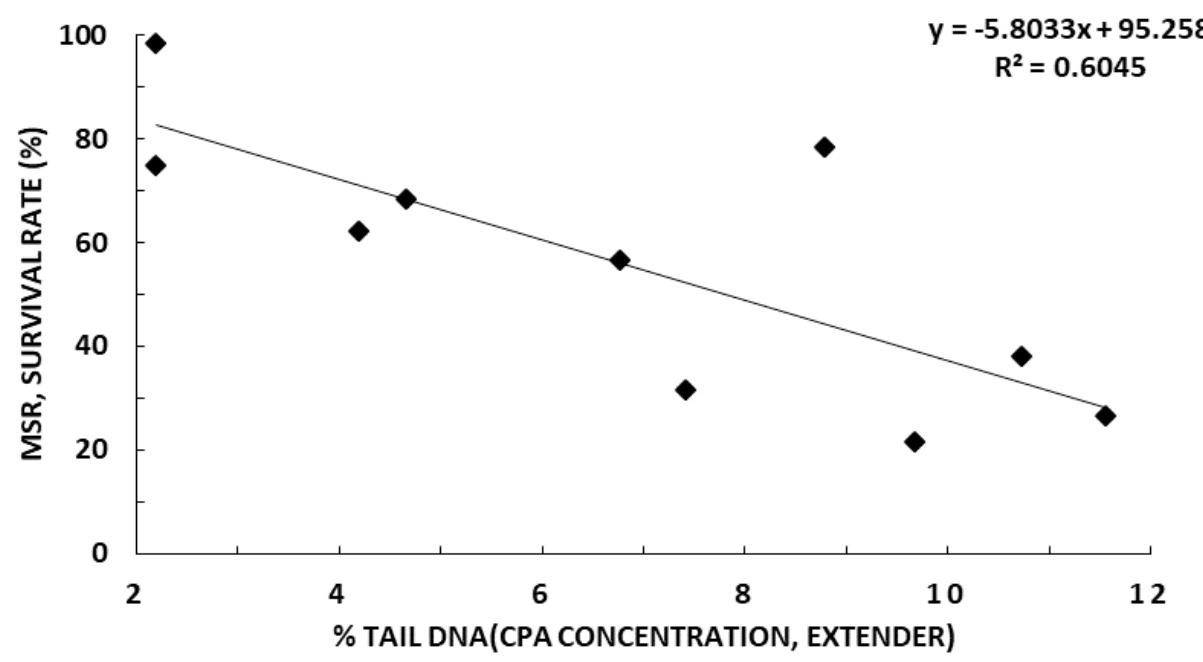

Fig. 8. Relationships between movable sperm ratio (MSR), survival rate \% (y), and \% tail DNA (CPA concentration, Extender) (x). $R^{2}$, Pearson's correlation coefficient; CPA, cryoprotective. 
Table 3. Results of the comet assay performed at various concentrations of ethylene glycol (EG) as the cryoprotective agent (CPA) with ASP (artificial seminal plasma of small yellow croaker) as the diluent in large yellow croaker (Larimichthys crocea)

\begin{tabular}{|c|c|c|c|c|c|}
\hline \multirow[t]{2}{*}{ Parameters } & \multirow[t]{2}{*}{ Control } & \multicolumn{4}{|c|}{ EG concentration (\%) } \\
\hline & & $5 \%$ & $10 \%$ & $15 \%$ & $20 \%$ \\
\hline Head length $(\mu \mathrm{m})$ & $60.6 \pm 0.65^{\mathrm{a}}$ & $54.82 \pm 0.1^{c}$ & $56.04 \pm 0.76^{b}$ & $55.96 \pm 0.74^{b}$ & $52.10 \pm 0.68^{d}$ \\
\hline Tail length $(\mu \mathrm{m})$ & $34.23 \pm 0.52^{\mathrm{e}}$ & $51.39 \pm 0.91^{b}$ & $40.79 \pm 1.08^{d}$ & $50.12 \pm 1.42^{c}$ & $54.97 \pm 1.53^{\mathrm{a}}$ \\
\hline Head intensity (\%) & $93.02 \pm 0.69^{\mathrm{a}}$ & $82.95 \pm 0.65^{c}$ & $86.71 \pm 0.94^{b}$ & $81.44 \pm 0.97^{d}$ & $75.99 \pm 1.12^{\mathrm{e}}$ \\
\hline Tail intensity (\%) & $6.98 \pm 0.69^{e}$ & $17.05 \pm 0.65^{c}$ & $13.29 \pm 0.94^{d}$ & $18.56 \pm 0.97^{b}$ & $24.01 \pm 1.12^{\mathrm{a}}$ \\
\hline Tail DNA (\%) & $2.19 \pm 0.22^{\mathrm{e}}$ & $6.77 \pm 0.29^{c}$ & $4.66 \pm 0.36^{d}$ & $7.42 \pm 0.50^{b}$ & $9.67 \pm 0.57^{\mathrm{a}}$ \\
\hline
\end{tabular}

Control, fresh sperm.

Table 4. Results of the comet assay performed after sperm cryopreservation with $10 \%$ EG as the cryoprotective agent (CPA) and various solutions as diluents in large yellow croaker (Larimichthys crocea)

\begin{tabular}{|c|c|c|c|c|c|c|}
\hline \multirow[t]{2}{*}{ Parameters } & \multirow[t]{2}{*}{ Control } & \multicolumn{5}{|c|}{ Different diluent } \\
\hline & & ASP & Cortland & HBBS & MFRS & Stein's \\
\hline Head length $(\mu \mathrm{m})$ & $60.6 \pm 0.65^{b}$ & $56.44 \pm 0.84^{d}$ & $58.16 \pm 0.73^{c}$ & $50.70 \pm 0.51^{e}$ & $50.23 \pm 0.74^{f}$ & $61.64 \pm 0.70^{a}$ \\
\hline Tail length $(\mu \mathrm{m})$ & $34.23 \pm 0.52^{f}$ & $39.93 \pm 1.01^{\mathrm{e}}$ & $58.05 \pm 1.04^{d}$ & $62.11 \pm 1.22^{c}$ & $63.78 \pm 1.37^{b}$ & $120.65 \pm 2.58^{\mathrm{a}}$ \\
\hline Head intensity (\%) & $93.02 \pm 0.69^{a}$ & $87.82 \pm 0.95^{b}$ & $78.63 \pm 0.84^{c}$ & $74.31 \pm 0.85^{d}$ & $71.41 \pm 0.86^{\mathrm{e}}$ & $57.31 \pm 0.80^{f}$ \\
\hline Tail intensity (\%) & $6.98 \pm 0.69^{f}$ & $12.18 \pm 0.95^{\mathrm{e}}$ & $21.37 \pm 0.84^{d}$ & $25.69 \pm 0.85^{c}$ & $28.59 \pm 0.86^{b}$ & $42.69 \pm 0.80^{a}$ \\
\hline Tail DNA (\%) & $2.19 \pm 0.22^{f}$ & $4.19 \pm 0.35^{\mathrm{e}}$ & $8.79 \pm 0.39^{d}$ & $10.73 \pm 0.48^{c}$ & $11.55 \pm 0.47^{b}$ & $27.95 \pm 0.70^{\mathrm{a}}$ \\
\hline
\end{tabular}

EG, ethylene glycol; Control, fresh sperm; ASP, artificial seminal plasma of small yellow croaker; HBBS, Hanks' balanced salt solution; MFRS, marine fish Ringer's solution; Stein's, Stein's solution.

frozen-thawed turbot spermatozoa (Cosson et al., 1999).

Freezing rate is a significant factor in sperm cryopreservation. In the present study, the optimal freezing rate was in the range of $-1{ }^{\circ} \mathrm{C}$ to $-10^{\circ} \mathrm{C} \mathrm{min}^{-1}$, indicating that these freezing rates could better prevent formation of intracellular ice crystals in sperms during the cryopreservation process than the other rates tested. The best freezing rate for sperm cryopreservation in large yellow croakers was $-10^{\circ} \mathrm{C} \mathrm{min}^{-1}$. Using this freezing rate, intracellular ice crystal formation during cryopreservation was prevented. The optimal post-thaw motility of large yellow croaker was achieved using a freezing rate of $20^{\circ} \mathrm{C} \mathrm{min}^{-1}$ with HBBS as the diluent and glycerol or DMSO as the CPA (Xiao et al., 2007). Theoretically, to minimize the exposure time of sperm to concentrated extracellular solutions, the freezing rate should be fast enough and yet slow enough to minimize the formation of intracellular ice crystals in sperms to below a damaging level through cellular dehydration. In other marine species, the optimal freezing rate varies among species such as $\operatorname{cod}\left(5^{\circ} \mathrm{C} / \mathrm{min}\right)$, hirame $\left(8^{\circ} \mathrm{C} / \mathrm{min}\right)$, sea bass $\left(10^{\circ} \mathrm{C} / \mathrm{min}\right)$, and sea bream $\left(10^{\circ} \mathrm{C} / \mathrm{min}\right.$ ) (Fauvel et al., 1998; Mounib, 1978; Suquet et al., 2000; Suquet et al., 2005; Tabata \& Mizuta, 1997).

During thawing, the same physiological processes take place in a reverse order as that during freezing. Theoretically, thawing rate should be the same as the corresponding cooling rate. The rate of temperature change must be well moderated to avoid additional stresses due to rates that are either too fast or too slow. In this study, $45^{\circ} \mathrm{C}$ was an effective thawing temperature, resulting in higher post-thaw sperm motility. According to Xiao et al. (2007), thawing in a $43^{\circ} \mathrm{C}$ water bath showed optimal post-thaw motility in large yellow croaker. Another experiment, using a thawing temperature ranging from $38^{\circ} \mathrm{C}$ to $40^{\circ} \mathrm{C}$, resulted in higher sperm motility in large yellow croakers than using temperatures outside this range (Lee \& You, 2002). In contrast, the optimal post-thaw sperm motility for small yellow croakers was observed when subjected to a $37^{\circ} \mathrm{C}$ water bath for $30 \mathrm{~s}$ (Le et al., 2011; Lim et al., 2010). In other marine species, the optimal thawing temperature is species-specific, with that of the Atlantic halibut, grouper, barramundi, bluefin tuna, and sea bass at $10^{\circ} \mathrm{C}-40{ }^{\circ} \mathrm{C}, 25^{\circ} \mathrm{C}, 30^{\circ} \mathrm{C}, 40^{\circ} \mathrm{C}$, and $35^{\circ} \mathrm{C}$, respectively (Bolla et al., 1987; Leung, 1987; Withler \& Lim, 1982).

In recent years, SCGE has been developed and established as a rapid and accurate system for identifying DNA damage in sperm (Zilli et al., 2003). In the present study, the lowest value of percentage of tail DNA was found in the control treatment (fresh 
sperm) at $2.19 \pm 0.22 \%$, followed by that using $10 \% \mathrm{EG}+\mathrm{ASP}$ treatment $(4.66 \pm 0.36 \%)$, which were significantly different to the values obtained using the other treatments. Investigation of DNA damage in large yellow croaker after cryopreservation using Cortland solution as the diluent and DMSO as the CPA at the concentration of 5\%-20\% showed no significant differences in motility, comet rate, and damage coefficient between fresh sperm and cryopreserved sperm (Xu et al., 2013; Xu et al., 2014). SCGE results showed that there were no significant differences in DNA fragmentation between fresh sperm and frozen-thawed sperm diluted with $5 \%-20 \%$ DMSO or $5 \%-20 \%$ EG; however, DNA damage to frozen-thawed sperm increased significantly at $25 \%$ DMSO or 30\% EG (Xu et al., 2014). Significant DNA damage occurred in cryopreserved European sea bass (Dicentrarchus labrax) sperm compared with fresh sperm, but the cryopreservation process did not affect motility or fertilization percentage (Zilli et al., 2003). Similar results were shown by Labbe et al. (2001), wherein DNA stability was lowered by cryopreservation of rainbow trout sperm, but survival rate and quality of sperm remained unaffected. The level of damage to fish sperm DNA is affected by several factors, including the species of fish, its chromosome structure, and the CPA and diluent used for the process of freezing and thawing (Lim et al., 2006; Liu et al., 2014).

\section{Conclusion}

In this study, the optimal cryopreservation protocols were determined for large yellow croaker. The use of 10\% EG as the CPA and ASP as the diluent resulted in the highest post-thaw sperm motility and the lowest percentage of tail DNA. Postthaw MSR in large yellow croakers appeared to be stable up to an equilibration time of $150 \mathrm{~s}$ and at dilution ratio of 1:1-1:3. Further, the freezing rate was found to be slow below $-10^{\circ} \mathrm{C} /$ min. Moreover, a thawing temperature of $45^{\circ} \mathrm{C}$ resulted in the highest post-thaw sperm motility.

\section{Competing interests}

No potential conflict of interest relevant to this article was reported.

\section{Funding sources}

Not applicable.

\section{Acknowledgements}

The authors are thankful to the Fisheries and Marine Sciences
Research Center, Jido for providing the fish used in the present study.

\section{Availability of data and materials}

Upon reasonable request, the datasets of this study can be available from the corresponding author.

\section{Ethics approval and consent to participate}

The ethics committee for The Institutional Animal Care and Use Committee of Mokpo National University No.1183 (17 December 2013) allowed this research.

\section{References}

Ahn JY, Park JY, Lim HK. Effects of different diluents, cryoprotective agents, and freezing rates on sperm cryopreservation in Epinephelus akaara. Cryobiology. 2018;83:60-4.

Bart AN, Wolfe DF, Dunham RA. Cryopreservation of blue catfish spermatozoa and subsequent fertilization of channel catfish eggs. Trans Am Fish Soc. 1998;127:819-24.

Berlinsky DL, King VW, Hodson RG, Sullivan CV. Hormone induced spawning of summer flounder Paralichthys dentatus. J World Aquac Soc. 1997;28:79-86.

Betsy J, Kumar S. Cryopreservation of fish gametes. Singapore: Springer; 2020.

Bolla S, Holmefjord I, Refstie T. Cryogenic preservation of Atlantic halibut sperm. Aquaculture. 1987;65:371-4.

Bozkurt Y, Yavaş İ. Cryopreservation of nile tilapia (Oreochromis niloticus) sperm. Cryopreserv Eukaryotes. 2016.

Cabrita E, Pacchiarini T, Sarasquete C, Herraez MP. 141. Development of a cryopreservation protocol for Senegalese sole testicular germ cells. Cryobiology. 2010;61:405.

Cabrita E, Robles V, Rebordinos L, Sarasquete C, Herráez MP. Evaluation of DNA damage in rainbow trout (Oncorhynchus mykiss) and gilthead sea bream (Sparus aurata) cryopreserved sperm. Cryobiology. 2005;50:144-53.

Chao NH, Liao IC. Cryopreservation of finfish and shellfish gametes and embryos. Aquaculture. 2001;197:161-89.

Chang YJ. Cryopreservation of tiger puffer (Takifugu rubripes) sperm. Dev Reprod. 1997;1:29-36.

Cheng S, Sheng Z, Zhu JQ, Wu XF. Effects of trehalose, bovine serum albumin, and sucrose, on the integrity of the plasma membrane of Pseudosciaena crocea semen after cryopreservation. Isr J Aquac Bamidgeh. 2015;67:1-12.

Cloud J, Patton S. Basic principles of fish spermatozoa cryopres- 
ervation. In Cabrita E, Robles V, Herráez P, editors. Method in reproductive aquaculture. Boca Raton, FL: CRC Press; 2008. p. 237.

Cosson J, Billard R, Cibert C, Dreanno C, Suquet M. Ionic factors regulating the motility of fish sperm. In: Gagnon C. editor. The male gamete: from basic to clinical applications. Vienna, IL: Cache Rive Press, 1999. p. 161-86.

Fauvel C, Suquet M, Dreanno C, Zonno V, Menu B. Cryopreservation of sea bass (Dicentrarchus labrax) spermatozoa in experimental and production simulating conditions. Aquat Living Resour. 1998;11:387-94.

Gwo JC. Cryopreservation of black grouper (Epinephelusmalabaricus) spermatozoa. Theriogenology. 1993;39:1331-42.

Gwo JC. Cryopreservation of yellowfin seabream (Acanthopagrus latus) spermatozoa (Teleost, Perciformes, Sparidae). Theriogenology. 1994;41:989-1004.

Harvey B. Cryopreservation of sarotherodon mossambicus spermatozoa. Aquaculture. 1983;32:313-20.

Jiang JH, Yan JQ, Zhu JQ, Yang WX. Sperm cryopreservation and the cytoarchitecture damage detection of Pseudosciaena crocea. J Agric Biotechnol. 2011;19:725-33.

Kho KH, Kang KH. Cryopreservation of pointhead flounder (Cleisthenes pinetorum herzensteini ) sperm. Korean J Ichthyol. 2003;15:213-8.

Kopeika E, Kopeika J, Zhang T. Cryopreservation of fish sperm. Methods Mol Biol. 2007;368:203-17.

Labbe C, Martoriati A, Devaux A, Maisse G. Effect of sperm cryopreservation on sperm DNA stability and progeny development in rainbow trout. Mol Reprod Dev. 2001;60:397-404.

Le MH, Lim HK, Min BH, Park MS, Chang YJ. Storage of yellow croaker Larimichthys polyactis semen. Isr J Aquac Bamidgeh. 2011a;63:7.

Le MH, Lim HK, Min BH, Park MW, Chang YJ. Semen cryopreservation of yellow croaker Larimichthys polyactis. Rev Fish Biol Fish. 2011b;21:789-97.

Le MH, Lim HK, Min BH, Son MH, Lee JU, Chang YJ. Diluents and cryoprotectants for cryopreservation of filefish Thamnaconus modestus sperm. J Aquac. 2008;21:54-9.

Lee D, You Y. Physiological characteristics and cryopreservation of Pseudosiaena crocea (Richardson) sperms. J Trop Oceanogr. 2002;21:69-75.

Lee YH, Park JY, Lee IY, Zidni I, Lim HK. Effects of cryoprotective agents and treatment methods on sperm cryopreservation of stone flounder, Kareius bicoloratus. Aquaculture.
2021;531:735969.

Leung LKP. Cryopreservation of spermatozoa of the barramundi, Lates calcarifer (Teleostei: centropomidae). Aquaculture. 1987;64:243-7.

Lim HK, An CM, Noh GA, Min BH. Effects of diluents and cryoprotectants on sperm cryopreservation in tarry flounder (Platichthys stellatus). J Aquac. 2007;20:173-7.

Lim HK, An CM, Son MH, Park MW, Kim EO, Byun SG. Effect of diluents and temperature on sperm storage in starry flounder (Platichthys stellatus). J Aquac. 2006;19:47-51.

Lim HK, Min BH, Jeong M, Choi BN, Le MH, Chang YJ. Cryopreservation of semen in dead yellow croaker, Larimichthys polyactis. Fish Aquat Sci. 2010;13:350-3.

Lim HK, Le MH. Evaluation of extenders and cryoprotectants on motility and morphology of longtooth grouper (Epinephelus bruneus) sperm. Theriogenology. 2013;79:867-71.

Lin DJ, Yoo YL, Chen BY. Variation of the motility and Ultrastructure of the frozen-thawed sperm in teleost, Pseudosiaena crocea (Richardson). J Fujian Norm Univ (Natur Sci Ed). 2006;22:71-6.

Liu QH, Ma DY, Xu SH, Xiao ZZ, Xiao YS, Song ZC, et al. Summer flounder (Paralichthys dentatus) sperm cryopreservation and application in interspecific hybridization with olive flounder (P. olivaceus). Theriogenology. 2015;83:703-10.

Mounib MS. Cryogenic preservation of fish and mammalian spermatozoa. J Reprod Fertil. 1978;53:13-8.

Pérez-Cerezales S, Martínez-Páramo S, Cabrita E, Martínez-Pastor F, de Paz P, Herráez MP. Evaluation of oxidative DNA damage promoted by storage in sperm from sex-reversed rainbow trout. Theriogenology. 2009;71:605-13.

Suquet M, Dreanno C, Fauvel C, Cosson J, Billard R. Cryopreservation of sperm in marine fish. Aquac Res. 2000;31:231-43.

Suquet M, Normant Y, Gaignon JL, Quéméner L, Fauvel C. Effect of water temperature on individual reproductive activity of pollack (Pollachius pollachius). Aquaculture. 2005;243:113-20.

Stein H, Bayrle H. Cryopreservation of the sperm of some freshwater teleosts. Ann Biol Anim Bioch Biophys. 1978;18:1073-6.

Tabata K, Mizuta A. Cryopreservation of sex reversed gynogenetic female sperm in hirame. Fish Sci. 1997;63:482-3.

Withler FC, Lim LC. Preliminary observations of chilled and deep-frozen storage of grouper (Epinephelus tauvina) sperm. Aquaculture. 1982;27:389-92.

Xiao Z, Chen X, Ding F, Liu Q, Xu S, Li J. An efficient methodology of sperm ceryopreservation of large yellow croaker 
(Pseudosciaena croce). Mar Sci. 2007;31:1-4.

Xu XR, Zhu JQ, Ye T, Wang CL, Zhu YF, Dahms HU, et al. Improvement of single-cell gel electrophoresis (SCGE) alkaline comet assay. Aquat Biol. 2013;18:293-5.

Xu XR, Tan FQ, Zhu JQ, Ye T, Wang CL, Zhu YF, et al. Detection of DNA damage caused by cryopreservation using a modified SCGE in large yellow croaker, Pseudosciaena crocea. Acta Biol Hung. 2014;65:405-13.

Zidni I, Lee YH, Park JY, Lee HB, Hur JW, Lim HK. Effects of cryoprotective medium composition, dilution ratio, and freezing rates on spotted halibut (Verasper variegatus) sperm cryopreservation. Animals. 2020;10:2153.

Zilli L, Schiavone R, Zonno V, Storelli C, Vilella S. Evaluation of DNA damage in Dicentrarchus labrax sperm following cryopreservation. Cryobiology. 2003;47:227-35. 